\title{
NARRAR EXPERIÊNCIA(S): \\ CONSTRUIR SENTIDOS SOBRE O FORMAR-SE PROFESSOR
}

Heriédna Cardoso Guimarães ${ }^{\mathrm{i}}$

\begin{abstract}
Resumo: Neste texto apresento um relato de experiência que intenciona ratificar a potencialidade das narrativas de histórias de vida e formação no desenvolvimento de processos de formação de professores e na construção de pesquisas que investigam os modos como os sujeitos professores se formam. Inicio propondo que as narrativas de experiências de vida e formação são potentes para a emersão dos imbricamentos entre vida e formação e desse modo recorro as contribuições da Pesquisa (Auto)Biográfica como modo de conexão entre as narrativas e os processos de formação. Sequencio apresentando a narrativa de uma experiência que vivi ao cursar uma disciplina eletiva ofertada por um Programa de Pós-Graduação em Educação de uma universidade federal, localizada no estado do Rio de Janeiro. Emergem desta escrita/narrativa reflexões que nos possibilitam olhar os formatos engessados de formação que experienciamos e como estes se perpetuam no nosso modo de produzir conhecimento e ser professor, identificado, neste texto, como o escrito-repetido-do-lido.
\end{abstract}

Palavras-chave: Narrativa; experiência; formação de professores.

\section{NARRANDO EXPERIENCIAS: CONSTRUYENDO SIGNIFICADOS ACERCA DE CONVERTIRSE EN UN MAESTRO}

\begin{abstract}
Resumen: En este texto presento una historia de experiencia que pretende ratificar la potencialidad de la narración de la vida y la educación en el desarrollo de los procesos de formación de profesores y en la construcción de investigaciones que investiguen las formas en que se forman los maestros. Comienzo proponiendo que las narraciones de la vida y las experiencias de formación son poderosas para la emersión de las imbricaciones entre la vida y la formación, y de esta manera recurro a las contribuciones de la Investigación (Auto)Biográfica como una forma de conectar las narraciones y los procesos de formación. Presento la narración de una experiencia que viví mientras asistía a un curso electivo ofrecido por un Programa de Posgraduado en Educación de una universidad federal ubicada en el estado de Río de Janeiro. De este escrito/narración surgen reflexiones que nos permiten mirar los formatos enyesados de formación que experimentamos y cómo éstos se perpetúan en nuestra forma de producir conocimiento y ser maestro, identificados en este texto como la reescritura de la lectura.
\end{abstract}

Palabras clave: Narrativa; experiencia; la formación de los profesores

\section{Narrativas, experiências e formação}

A ação de narrar, intercambiar experiência, como aponta Walter Benjamin (2012), é inerente ao humano, ser falante que escuta e faz uma leitura singular ao narrar o vivido ou ao narrar sobre si; os viajantes e artesãos foram, por muitos séculos, os narradores por excelência, mas com o advento da técnica e a inserção tecnológica como modus operandi de vida, estes perderam seus espaços-tempos dedicados ao narrar experiências que carregam em si um saber, um 'conselho' que se aproxime do conselho dado aos 
filhos pelo vinhateiro em seu leito de morte, pois há um tesouro oculto nos vinhedos, basta desenterrá-lo! O saber que emerge deste conselho como sentido do vivido foi reconhecido e ressignificado pelos filhos quando estes se dedicaram a cavar os vinhedos obtendo, à época, a melhor colheita da região. O tesouro não estava enterrado, mas foi construído a partir do movimento que a narrativa iniciou, movimento de sentidos e leituras que produzem um saber, uma dinâmica que impele para o futuro, partindo do tempo de agora e carregando, consigo, o pretérito.

É o movimento do passado que nos impele a pensar no presente e construir um/ou muitos futuros e, nesse ir e vir, olhando para o pretérito e narrando no agora, olhamos para nossas experiências, fazemos leituras de si e narramos saberes experienciais que nos impelem a pensar criticamente, a tornar "canto" como sinalizado por Jorge Larrosa, porque

[...] a experiência não é uma realidade, uma coisa, um fato, não é fácil de definir nem de identificar, não pode ser objetivada, não pode ser produzida. E tampouco, é um conceito, uma ideia clara e distinta. A experiência é algo que (nos)acontece e que ás vezes treme, ou vibra, algo que nos faz pensar, algo que nos faz sofrer ou gozar, algo que luta pela expressão, e que às vezes, algumas vezes, quando cai em mãos de alguém capaz de dar forma a esse tremor, então, somente então, se converte em canto (LARROSA, 2019, p. 10).

As leituras que construímos dos acontecimentos que nos passam é já um sentido primeiro que construímos e externamos, uma vez que "os atos de pensar e escrever sobre as experiências não conduzem somente ao ato de refletir sobre o passado, mas também potencializam a percepção de como essas experiências vividas anteriormente influenciam no presente" (DOMINGO; SIMAS, 2018, p. 66). Ou seja, o presente e o futuro, marcos temporais inerentes à condição de sujeitos que somos, não são puros, se aproximam mais de amálgamas de passados, presentes, desejos, cultura, história, entre outros, que, uma vez orientados por uma temporalidade que é construída pelo sujeito, podem produzir, ou não, futuros irrefletidos que chocam os sujeitos via as frustrações, à alimentação ininterrupta de estereótipos econômicos/profissionais inalcançáveis.

Nesse sentido, a narrativa de experiências se configura como um, ou vários, espaço(s)-tempo(s) para a reflexão acerca dos modos como vivemos as nossas experiências de formação e, em especial, para pensarmos sobre como estas nos (trans)formaram enquanto pessoas que construíram e constroem seus processos de formação e estéticas profissionais. Ou seja,

[...] a perspectiva (auto)biográfica de pesquisa ao se preocupar com o resgate da narrativa do sujeito, e sua construção e reconstrução de fatos vividos, tal como ele os compreende e rememora, tem a preocupação e o desejo de que o saber da experiência assuma a centralidade, proporcionando não só novas perspectivas e sentidos às dinâmicas dos processos formativos, como também ressituá-los em suas 
inscrições sociais e históricas, num movimento dialético entre o individual e o coletivo (HENRIQUES, 2018, p. 6-7).

Ampliando as expectações em relação à construção de pesquisas (auto)biográficas, encontramos nas contribuições de Delory-Momberger que “o objeto [das pesquisas (auto)biográficas] é o de explorar os processos de gênese e de vir-a-ser dos indivíduos num espaço social, mostra[ndo] como eles dão forma as suas experiências, como fazem significar as situações e os acontecimentos de sua existência" (p. 71, 2012). As significações que emergem com o biográfico ${ }^{i i}$ da vida são compostas pelas relações, bem como as implicações dos diversos sociais e culturais que transpassam o sujeito que narra as suas experiências.

No movimento de construção da narrativa é importante a não dissociação entre temporalidade e tessitura do narrado, de modo que a "presença do indivíduo no mundo social ... é resultante de uma experiência no tempo: o indivíduo vive o espaço social como uma sucessão temporal de situações e acontecimentos" (DELORY-MOMBERGER, 2012, p. 73), oportunizando à pesquisa (auto)biográfica, o compromisso de compreender "como" os sujeitos constroem-se e são construídos pelo e com os espaços sociais que aparecem via a sua individualidade que é preservada, em especial, nas escolhas temporais que fazem ao narrar suas experiências de vida e formação. Uma vez que a autonomia do sujeito no movimento de autoria narrativa não é silenciado, é possível perceber que a singularidade inerente ao sujeito não se configura somente como desdobramento de um dado contexto social, institucional, cultural, mas, especialmente, das opções temporais que o sujeito integra e significa no enredo de sua narrativa.

Uma vez admitida a centralidade do sujeito que segue a lógica de uma razão narrativa, como proposto nas contribuições hermenêuticas e fenomenológicas e mobiliza a sucessão temporal coerente ao enredo que deseja para a narrativa de sua experiência, é possível dizer que nessa

[...] lógica, o indivíduo humano vive cada instante de sua vida como o momento de uma história: a história de um instante, história de uma hora, de um dia, história de uma vida, algo começa, se desenvolve, chega a seu termo, numa sucessão, num encaixe, um empilhamento indefinido de episódios e de proezas, provas e de experiências (DELORY-MOMBERGER, 2012, p. 73-74).

É, ao organizar esse empilhar aleatório que o sujeito realiza a reflexão em torno de sua vida e imbricamentos diversos de modo que nesse espaço do biográfico, da escrita de si, o sujeito apresenta os modos como se constrói e significa as diversas e infinitas relações que a vida em sociedade suscita. É por causa da opção racional, pela construção de um enredo que necessita de organização temporal, realizado pelo sujeito, que a narrativa de uma experiência fala de coletivo e não só de indivíduo, pois

[...] as 'histórias' que contamos sobre nós mesmos e que, segundo alguns, nós dirigimos a outros, longe de nos jogar numa intimidade inacessível, têm por efeito articular nosso espaço-tempo individual ao espaço-tempo social. Efeito que pode 
ser obtido só porque a sequência narrativa que construímos, em suas formas e seus conteúdos, implica um conhecimento dos contextos, das instituições, das práticas, pois ela põe em cena uma racionalidade social na qual estamos envolvidos (DELORY-MOMBERGER, 2012, p. 75).

Ou seja, o ato de narrar, sobretudo, narrar experiências de formação, é produção de leituras de si e dos espaços sociais que habitam em nós e que tentamos modificar ou não. Porém, não é fácil e muito menos básico trabalhar com as narrativas nos processos de construção de pesquisas. Ao optar por trabalhar com as narrativas de experiências é imperativo ao pesquisador a compreensão de que ele é um sujeito que narra muito mais que sua vida e faz uso da pesquisa para esse feito. É somente a partir desse reconhecimento que ele consegue olhar para os sujeitos que o auxiliam na construção da pesquisa como sujeitos que falam/ narram os modos como nos apropriamos e interagimos com e nas instituições e contextos que vivenciamos, produzindo sentidos e leituras de vida. Nesse sentido, é necessário cautela e atenção, uma vez que

[...] a complexidade da relação de uma vida (do pesquisador) com outra vida (narrador) nem sempre aparece presente, evidenciando, em alguns momentos, oscilações paradigmáticas e a falta de preparo para lidar com os aspectos subjetivos da riqueza do material que se fez emergir (BARREIRO; ERBS, 2016, p. 71).

Uma vez iniciada a compreensão em torno dos objetivos da pesquisa (auto)biográfica da sua conexão direta com as narrativas de histórias de vida e formação é interessante sinalizar que, dentro do movimento (auto)biográfico em educação no Brasil, temos, seguindo a proposição de Maria da Conceição Passeggi e Elizeu Clementino de Souza (2016, p. 12) “dois grandes períodos: um primeiro momento de eclosão do autobiográfico e das histórias de vida em Educação, que emerge nos anos 1990, e um segundo momento de expansão e diversificação dos temas de pesquisa, que se inicia nos anos 2000". Junto a estes momentos temos as infinitas e imensuráveis contribuições das oito edições do Congresso Internacional de Pesquisa (Auto)Biográfica (CIPA) que acontecem, bianualmente, desde 2004 e reúne os pesquisadores e sujeitos que optam por realizar pesquisas (auto)biográficas.

No bojo das pesquisas (auto)biográficas, remeto-me, neste texto, ao cenário brasileiro. Há diferentes modos de se caminhar, pois o trabalho com as narrativas de experiências de vida e formação podem se configurar como método teórico-metodológico. Passeggi e Souza (2016) falam de quatro grandes orientações que foram seguidas pelas pesquisas (auto)biográficas no Brasil.

A primeira considera as narrativas autobiográfica como um fenômeno antropológico. Nesse sentido, interessa-se pelos processos de individuação e de socialização dos seres humanos, interrogando-se sobre como nos tornamos quem somos. A segunda orientação utiliza as narrativas como fonte e método de investigação qualitativa, indagando-se sobre práticas sociais, não apenas para produzir conhecimento sobre essas práticas, mas para perceber como os indivíduos dão sentido a elas. A terceira orientação faz uso dessas narrativas como dispositivos 
de pesquisa-formação, instituindo o sujeito como pessoa interessada no conhecimento que ela produz para si mesma (Souza, 2006 a). Finalmente, a quarta orientação estuda a natureza e a diversidade discursiva das escritas (grafias) da vida (bios) (PASSEGGI; SOUZA, 2016, p. 10).

É importante sinalizar que o início da pesquisa (auto)biográfica nas pesquisas em educação, no Brasil concentrou-se, em especial nos anos 1990, majoritariamente, na temática da formação de professores, ampliando leituras para o campo da didática, identidade docente, profissionalização, entre outros, e, somente a partir dos anos 2000 que outras leituras, como a pesquisa-formação, começaram a ganhar fôlego.

Em relação a localização deste texto dentro das quatro orientações elencadas acima e considerando o meu movimento pessoal/coletivo/formativo de imersão e diálogo com as narrativas em contexto de pesquisas, posso afirmar que é complicado localizar-me em uma única orientação. Considero que transito entre a primeira e a segunda porque sempre questiono, ao ler as narrativas de história de vida e formação, como nos tornamos os professores que somos? Porém, não consigo ignorar, e, às vezes, recorro a esse olhar mais que à pergunta anterior, os sentidos que as pessoas atribuem às práticas sociais que viveram e às vezes reproduzem de forma não consciente ou não reflexiva, além de sempre reafirmar que a presença das narrativas nas pesquisas em educação está em total diálogo com os princípios da investigação qualitativa.

A tentativa de localização não é engessada, mas localizada no espaço-tempo desta escrita, e pode modificar-se no futuro, porém, acredito que ela se faz necessária para delinear os olhares e até mesmo a consonância teórico-empírico entre narrativa, experiência e formação, cujo tecido fundante é a vida. Considerando essa coesão sequencio este texto com a narrativa de uma experiência que vivi ao cursar uma disciplina eletiva ofertada por um Programa de Pós-Graduação em Educação, de uma universidade federal, localizada no estado do Rio de Janeiro que objetivava discutir a temática da Pesquisa (Auto)Biográfica.

\section{A disciplina como experiência: o que consigo narrar}

Eu tinha adaptado minhas lembranças para dar coerência à minha representação do passado. [...] Era lógico, porém falso. [...] Graças a essa adaptação, eu não era prisioneiro do passado e escapava ao trauma (CYRULNIK, 2013) .

Admitindo que caminho adaptando "minhas lembranças", de modo a torná-las coerentes, neste texto e, ao mesmo, tempo feliz porque as adaptações memoriais que apresento na sequência não são tentativas de fuga de nenhuma experiência traumática, intenciono, nesta parte, narrar a experiência que construí ao longo das aulas e diálogos que o espaço-tempo chamado disciplina contextualizou, mas que foi semanalmente lapidado, construído entre linguagem formal/informal pelas diferentes vozes e olhares dos alunos e docente responsável pela disciplina. 
Para mim, iniciamos os diálogos pensando na construção de uma crítica indireta à linguagem científica, em especial aos modos de produzir conhecimento. Estas leituras críticas iniciais transitaram desde a inserção da pesquisa (auto)biográfica na educação e no Brasil até a crítica construída por Franco Ferrarotti (2010), para o uso secundário das narrativas de histórias de vida nas pesquisas realizadas no âmbito da sociologia, modo que reduz as biografias/histórias de vida a complementos de dados nas pesquisas. Não! As narrativas das histórias de vida dos sujeitos devem e podem ser a fonte empírica primária, podendo ser colocadas em diálogo com outras fontes de dados; as diferentes fontes secundárias aparecem como modos de escrever sobre os contextos sociais, institucionais, modos e leituras culturais e não como meio/modo para confirmar, ratificar a experiência narrada, o que reduziria as pesquisas que dialogam com as narrativas das histórias de vida e formação à polarização verdadeiro ou falso.

Ler o Ferrarotti, quase um ano após a conclusão da dissertação de mestrado em educação, livre da pressão de escrever sobre o autor ou de colocar as suas ideias em diálogo com o meu tema de dissertação, é alentador, pois propicia olhar o pretérito e pensar os caminhos que segui no trabalho com as narrativas na construção da pesquisa de mestrado; seus avanços, aproximações e afastamentos, que nesta atualidade me auxiliam a construir a pesquisa desenvolvida para a escrita da tese. Tudo mudou! Eu mudei!

$\mathrm{Na}$ pesquisa de mestrado, as narrativas de histórias de vida e formação dos licenciandos e professores foram as únicas fontes de dados analisadas. Não recorri às fontes secundárias ao construir a análise, mas recorri às fontes secundárias, terciárias, como o currículo, a história da universidade e do instituto de física para contextualizar e criar um cenário textual que seja comum a todos os sujeitos da pesquisa, inclusive eu; no caso da minha dissertação o cenário/contexto comum as nossas histórias de vida e formação foi o Instituto de Física porque os docentes trabalham lá e eu e os licenciandos cursamos toda a licenciatura em física no mesmo espaço, em tempos próximos, mas ainda assim diferentes. Pertencíamos, de diferentes modos, ao mesmo contexto institucional e o enxergávamos a partir de diferentes focos.

No texto composição de histórias que é a minha dissertação - para mim a minha dissertação é isso , algumas histórias são apresentadas sob a forma de escrita acadêmica, prenhe de citações, leis, datas, documentos e outras são narrativas apresentadas sob a forma de mônadas. Construí essa composição tentando sinalizar a impossibilidade de dissociação entre sujeitos, processos de construção de pesquisas, produção de conhecimento e formação de professores de física.

No contexto da disciplina, para além de revisitar a reflexão em torno da possibilidade de escrever triangulando (num plano horizontal) as diferentes fontes, sejam elas primárias, secundárias, de tipo documental, fotográfico, etc., foi possível perceber aproximações entre os escritos de Ferrarotti e a defesa por uma "sociologia do sujeito" construída por Bernard Charlot. Ambos sociólogos - Franco Ferrarotti (2010) e Bernard Charlot (2000) -, experienciando espaços-tempos diferentes, sinalizam que a sociologia ao aproximar-se do paradigma positivista de produção do conhecimento, abandonou o seu principal objeto, 
o sujeito. Ler Bernard Charlot suscitou diferentes olhares, em especial, para o lugar do sujeito nas nossas pesquisas. Quais espaços dedicamos aos sujeitos de nossas pesquisas? O que significa ser sujeito no contexto de uma pesquisa? Não sei ao certo as respostas, mas se conseguirmos não dissociar a pessoa que fala do que é falado, se admitirmos que a pessoa que fala é um sujeito desejante, que está e é historicamente e espaço-temporalmente situada, produto e construção ativa deste contexto/espaço-tempo que é histórico, social e cultural, já estamos avançando muito em meio à estética econômica e globalizante do modelo capitalista.

Charlot (2000) inicia o texto apresentando o que é o sujeito para ele, um ser humano aberto ao mundo, um ser social e singular, que age no mundo e se produz no mundo, e que é produzido por ele; o sujeito é um ser humano ativo e de práxis. Seguindo essa leitura, acerca do que é o sujeito, ele faz uma releitura das teorias sociológicas contemporâneas que se construíram sem considerar o sujeito e seu inconsciente, o sujeito e sua potência de construção adversa aos controles e rótulos sociais, seus modos de apropriação do social, afinal, até o silêncio pode ser uma opção do sujeito.

De uma sociologia sem sujeito (DURKHEIM, 2007 e BOURDIEU, 1996, 2008) passa pela sociologia da subjetivação (DUBET, 1994) - que mesmo sendo uma sociologia da ação desconsidera a ação individual do sujeito sobre si mesmo e no mundo - e chega até "o fantasma de outrem que cada um carrega em si" (CHARLOT, 2000, p. 45), através do diálogo com a psicologia. O diálogo entre a psicologia e a sociologia é, para Charlot (2010), fundamental e se configura como um modo de alcançar um feito que a sociologia não conseguiu, que é admitir a individualidade do sujeito, assumir que, as dinâmicas vividas pelo sujeito, são fruto de apropriação do social, uma elaboração psíquica do social que acontece via determinados processos internos. Todavia, como coloca Charlot (2000), não são todas as teorias construídas no âmbito da Psicologia que podem auxiliar a Sociologia na busca por um olhar mais completo para o sujeito pois, assim como o sujeito racional da filosofia moderna e a redução do sujeito a um fato social, realizada por Durkheim não contribuem muito, a leitura extremamente biológica e lógica de Piaget também não.

É importante lembrar que estamos falando de uma relação consigo mesmo que passa sempre pelo outro; a relação do saber, seja sobre si, sobre o mundo, etc. passa sempre pela relação com o outro e por isso é, o "fantasma" do outro, que carregamos em nós. As leituras de Wallon e Vigotski avançaram muito neste sentido. O sujeito, que a psicologia apresenta à ciência, é o elemento que falta à sociologia para que a relação com o saber seja observada a partir do olhar do sujeito desejante, construtor de sentidos para sua história. É este sujeito desejante que Bernard Charlot apresenta como o sujeito que não fracassa, afinal, o fracasso escolar é um rótulo que a escola criou para silenciar o desejo aprendente do sujeito, o desejo de tornar-se humano, pois "pode-se considerar que a essência do ser humano é tudo o que a espécie humana 
criou no decorrer de sua história. Portanto, a educação é um processo de humanização, socialização e subjetivação" (CHARLOT, 2010, p. 151).

Desejo destacar, referente à dinâmica adotada na construção da disciplina, os espaço-tempos das aulas destinados à leitura e escuta coletiva de nossas percepções construídas a partir da experiência de leitura e discussão dos textos que compunham a bibliografia básica da disciplina e que nós, individualmente ou não, nos responsabilizamos pela orientação sutil do diálogo no decorrer das aulas. Ou seja, para cada aula, os alunos, um ou dois, se responsabilizavam por orientar e apresentar as principais ideias do texto a ser estudado e, na aula seguinte, este mesmo aluno fazia a leitura para a turma de suas percepções construídas a partir do desenvolvimento da aula anterior. Essa escrita perceptiva era compartilhada com todo o grupo via a leitura coletiva e via arquivo digital. Importante dizer que em nenhum momento a responsabilidade por orientar o estudo do texto recaiu na fala única do aluno responsável, ou em apresentações em power-point dos textos; essa responsabilidade foi significada como artesania inerente ao olhar humano, com diálogo, dúvidas, leituras que avançavam para além do escrito no texto.

As minhas leituras dos escritos perceptivos para os colegas e a professora, sempre tiveram uma escuta atenta e sensível, recaindo em novos olhares e ressignificações em torno dos modos de produzir conhecimento e como essa produção/construção não está descolada da vida, de nosso eu pessoal, profissional que por vezes é silenciado. Mas, minhas percepções, em geral, eram todas muito técnicas, a exemplo do que escrevi acima em relação ao texto de Bernard Charlot. Ou seja, consegui escrever e ler, para os meus colegas, percepções que se aproximam mais de um esboço de resenha, fiel às principais ideias do texto, e não percepções que eu construí via a conversa, percepções em relação à leitura/estudo coletivo, aos avanços compreensivos, ou mesmo percepções que relacionem aproximações, afastamentos das leituras dos colegas.

Admito que segui o roteiro formal, signifiquei a escrita das percepções com a escrita de um resumo do texto e não com o que a leitura/ estudo coletivo do texto transformou em mim. Não ousei afastar da linguagem acadêmica, não ousei falar sobre o modo como os meus colegas me auxiliaram naquele espaçotempo chamado aula, naquela tarefa de estudar junto mesmo após realizar a leitura individual. O modo como nos colocamos em relação à leitura e escrita é importante porque nós, enquanto alunos - se estamos na graduação ou na educação básica vivemos com o terror iminente da avaliação/prova e se experienciamos a pós-graduação convivemos com a responsabilidade de síntese voltada para o uso rápido e aligeirada na escrita dos trabalhos finais e publicações, pois, precisamos ser produtivos, diz-nos a CAPES $S^{\text {iii }}$; - por vezes, nos esquecemos que somos sujeitos de nossas escritas, responsáveis pelo que defendemos ou criticamos ao escrever e, mais importante ainda, esquecemos de construir algo novo e recaímos na automática escritarepetida-do-lido, que poderia ser recriada e ressignificada em cada nova leitura e escrita, mesmo mantendo 
o rigor conceitual. A professora responsável pela turma foi a única que disse que faltava eu nas escritas perceptivas.

Foi a escrita-repetida-do-lido que mais apareceu nas minhas narrativas perceptivas construídas com a turma e, por isso, é importante perguntar: ao ler junto com os colegas de turma as escritas-repetidas-dolido fica nítido que me distanciei da capacidade humana de intercambiar experiências que partem da vida, como propõem Walter Benjamin e Jorge Larrosa? As nossas experiências de formação estão nos formatando de tal modo que as nossas experiências de leitura/escrita seguem irreflexivamente roteiros do tipo escrita-repetida-do-lido? Sem a pretensão de encerrar as possibilidades de respostas às questões, posso dizer que, para mim, as duas respostas estão mais para sim do que para não.

As contribuições de Vigotski (2009) para os modos como internalizamos as funções superiores, nos ajudam a entender a adoção total da linguagem acadêmica e, portanto, a naturalização referente ao uso deste modo de falar/escrever nossas experiências. É como se todas as experiências necessitassem seguir um único significado, mesmo que prenhe de diferentes sentidos, pois a linguagem técnica que aparece na narrativa é a transformação do pensamento em linguagem, esta desdobra o pensado e nós, após os vários anos de formação que experienciamos, não conseguimos perceber de forma imediata as formulações técnicas que utilizamos para falar o que pensamos. Internalizamos sentidos sobre o que e como dizer coisas na academia, que também constituem a nossa relação com o conhecimento e particularmente com o conhecimento instituído.

Seguindo o movimento de construção da disciplina é importante sinalizar que a escolha dos textos ${ }^{\text {iv }}$ foi fluída e nos possibilitou dialogar com a temática da formação de professores e a Pesquisa (Auto)Biográfica. Este diálogo aconteceu via as proposições da professora Inês Bragança (2011) e Maria Isabel da Cunha (2013). Recordo-me que no contexto da dissertação de mestrado, o texto de tese da professora Inês Bragança foi companheiro constante e me auxiliou a compreender as implicações filosóficas e sociológicas que a Pesquisa (Auto)Biográfica oferece à educação e, em especial, à formação de professores pois como nos sinaliza Couceiro e Inês ratifica no decorrer de seu texto,

[...] de algum modo as Histórias de Vida são uma "mediação" para a formação. Não no sentido de as considerar como uma técnica de formação, mas como uma abordagem que produz, ela própria, um certo tipo de formação e um certo tipo de conhecimento. Ou seja, as Histórias de Vida influenciam a natureza da formação que se produz, introduzindo mesmo uma ruptura epistemológica no conceito de formação (COUCEIRO, 2002, p. 157 apud BRAGANÇA, 2011, p. 158).

É formação que parte da vida e à vida se reconecta via a construção de experiências que nos transformam pois a educação consiste na apropriação/recriação do conhecimento acumulado pela humanidade, conhecimento que construímos socialmente, e a formação, como coloca Inês Bragança (2011, 
p. 159), "é um processo interior; ela liga-se à experiência pessoal do sujeito que se permite transformar pelo conhecimento". Desse modo, são as narrativas de nossas experiências de vida e formação que nos reconectam com o espaço-tempo da reflexão/significação/produção de sentidos acerca dos nossos processos de formação/autoformação. É compreender que vou me formando professora/pessoa no diálogo incessante com os outros, com os "fantasmas" que habitam em nós, nos transformando via as experiências que construímos.

Uma vez que o professor cria sua estética profissional/pessoal ele o faz

[...] a partir de inúmeras referências. Entre elas está sua história familiar, sua trajetória escolar e acadêmica, sua convivência com o ambiente de trabalho, sua inserção cultural no tempo e no espaço. Provocar que ele organize narrativas destas referências é fazê-lo viver um processo profundamente pedagógico, onde sua condição existencial é o ponto de partida para a construção de seu desempenho na vida e na profissão. Através da narrativa ele vai descobrindo os significados que tem atribuído aos fatos que viveu e, assim, vai reconstruindo a compreensão que tem de si mesmo (CUNHA, 2010, p. 202).

A professora Inês Bragança, em diálogo com as colocações do professor António Nóvoa, nos faz um alerta para que não associemos a inserção das narrativas das histórias de vida e formação, nos processos de formação de professores e adultos, com a ideia mercadológica e meritocrática de formação ao longo da vida (lifelong learning), responsabilizando o sujeito por todas as partes do processo de formação. O formarse perpassa toda uma vida, necessita do diálogo e imbricamento entre diferentes contextos, instituições e sujeitos, adquire dinâmicas por vezes coletivas, mas também admite movimentos individuais. Formação pessoal e profissional não podem ser reduzidas a uma receita, um currículo, uma política de formação, ambas passam essencialmente pela subjetividade; a subjetividade de cada sujeito media a construção e o desenvolvimento do formar-se professor/pessoa e ser pessoa/professor.

Nesse sentido, ao possibilitar e defender a abertura ao emergir da subjetividade nas pesquisas em educação, em especial naquelas que discutem a formação de professores, a pesquisa (auto)biográfica desponta como um modo teórico-metodológico potencial para a compreensão dos modos como os professores se formam e intencionam prosseguir com o seu processo de formação.

Caminhando para a tentativa de finalização desta narrativa, desejo falar da parte final da disciplina que teve como foco o diálogo entre as contribuições da pesquisa (auto)biográfica e os nossos projetos de pesquisas que se iniciam ou estão em desenvolvimento. Neste momento todos os discentes apresentaram os seus projetos e ambos partiram de um esboço de seus memoriais. Os esboços de nossos memoriais tinham, como princípio primeiro, trazer o imbricamento entre a nossa história de vida e formação e o tema de nossas pesquisas. Como construímos e escolhemos os nossos temas/objetos de pesquisa? Quais espaçostempos de nossa história de vida nos movem a realizar a pesquisa que estamos propondo? 
Escrever o memorial, ou mesmo esboçar esta escrita pensando nestas questões nos possibilita perceber muitas nuances, em especial, se estamos abertos à pesquisa, ao desconhecido que os caminhos da pesquisa e os sujeitos podem nos oferecer, ou se intencionamos somente confirmar algo que acreditamos ser o melhor para determinado tema. A mirada retrospectiva, orientada pela temática da pesquisa, possibilita a nós reconhecer os modos como significamos o nosso formar como pessoa e profissional, podendo suscitar até os nossos preconceitos e olhares viciosos para os contextos de nossas pesquisas.

Quero destacar que a disciplina não se encerra nesta narrativa e esta narrativa não encerra a experiência construída com e no contexto da disciplina, ela cria um cenário, um enredo, uma temporalidade que é única em cada narrativa e abre espaço para a construção de outras leituras, outras temporalidades possíveis aos sujeitos que narram. Eis o sentido fundante da narrativa de histórias de vida e formação, a abertura ao novo que parte de um pretérito, nos passa no presente e possibilita futuros mais contextualizados.

\section{Narrativa e fim: sempre tentativas de conclusão}

Finalizar este texto com uma síntese das ideias iniciais e como elas se conectam de modo a compor o enredo que ele é, seria um escrito-repetido-do-lido que, parece-me, ser desnecessário. A escrita/narrativa acima apresentada e significada como escrita-repetida-do-lido, possibilita olhar para a formação de professores como um espaço-tempo de ação que por vezes é uma repetição do vivido, repetição sem reflexão acerca dos modos como nos tornamos professores. Nesse sentido, a narrativa das histórias de vida e formação se mostram como potentes para que esses modos, para as nossas repetições dos escritos dos lidos possam aparecer e nos sinalizar que somos autores de nossos fazeres docentes, que mesmo imerso ao currículo, à cultura escolar, às práticas e discursos institucionais, podemos sim fazer da docência, um espaço-tempo de artesania e não de repetição.

\section{Referências}

BARREIRO, Cristhianny Bento; ERBS, Rita Tatiana Cardoso. Métodos, metodologias e teorias nas pesquisas em educação: explorando sentidos das narrativas. In: BRAGANÇA, I; ABRAHÃO, M. H.; FERREIRA, M. (Orgs.) Perspectivas epistêmico-metodológicas da pesquisa (auto)biográfica. Curitiba: CRV, p. 67-79, 2016.

BENJAMIN, Walter. Magia e técnica, arte e política: ensaios sobre literatura e história da cultura; tradução Sérgio Paulo Rouanet; prefácio Jeanne Marie Gagnebin - 8 ed. revista - São Paulo: Brasiliense, 2012. (Obras escolhidas v. 1).

BOURDIEU, Pierre. (Orgs.). A Miséria do mundo; sob direção de Pierre Bourdieu; com contribuições de Alain Accardo et. al. $17^{\circ}$ ed.- Petrópolis, RJ: Vozes, 2008. 
BOURDIEU, Pierre. Razões práticas: sobre a teoria da ação; tradução Mariza Correa. $9^{\circ}$ ed. - Campinas, SP: Papirus. 1996.

BRAGANÇA, Inês Ferreira de Souza. Sobre o conceito de formação na abordagem (auto)biográfica. Educação, Porto Alegre, v. 34, n. 2, p. 157-164, 2011.

CHARLOT, Bernard. Desafios da educação na contemporaneidade: reflexões de um pesquisador Entrevista com Bernard Charlot. Entrevista concedida a Teresa Cristina Rego e Lucia Emilia Nuevo Barreto Bruno. Educação e Pesquisa, São Paulo, v. 36, n. especial, p. 147-161, 2010.

CHARLOT, Bernard. Por uma sociologia do sujeito. In: CHARLOT, Bernard. CHARLOT, Bernard. $D a$ relação com o saber: elementos para uma teoria. 1. ed. Porto Alegre: ARTMED, 2000, p. 33-49.

CUNHA, Maria Isabel da. O tema da formação de professores: trajetórias e tendências do campo na pesquisa e na ação. Educação e Pesquisa, São aulo, v. 39, n. 3, p. 609-625, 2013.

CUNHA, Maria Isabel da. Narrativas e formação de professores: uma abordagem emancipatória. In: SOUZA, E. C.; GALLEGO, R. (orgs.). Espaços, tempos e gerações: perspectivas (auto)biográficas. São Paulo: Cultura Acadêmica, pp. 199-213, 2010.

CYRULNIK, Boris. Corra, a vida te chama: memórias; tradução Rejane Janowitzer. - 1. ed. - Rio de Janeiro: Rocco Digital, 2013. [versão digital].

DELORY-MOMBERGER, Christine. A pesquisa biográfica: projeto epistemológico e perspectivas metodológicas. In: ABRAHÃO, M.H.; PASSEGGI, M. (org.). Dimensões epistemológicas e metodológicas da pesquisa (auto)biográfica: Tomo I. - Natal: EDUFRN; Porto Alegre: EDIPUCRS; Salvador: EDUNEB, p. 71- 93, 2012.

DOMINGO, Jesus; SIMAS, Vanessa França. Narrar o passado e pensar o futuro: possibilidades na formação inicial de professores através da escrita de si. Conhecimento e Diversidade, v. 10, n. 20, p. 6283, 2018.

DUBET, François. Sociologie de l'expérience. Paris: Seuil, 1994.

DURKHEIM, Émile. As regras do método sociológico; tradução Paulo Neves; revisão da tradução Eduardo Brandão. $3^{\circ}$ ed. - São Paulo: Martins Fontes, 2007.

HENRIQUES, Eda Maria de Oliveira. Dimensões subjetivas, sociais e formativas do aporte (auto)biográfico em educação: alguns aspectos epistemológicos e metodológicos. Anais do VIII CIPA Congresso Internacional de Pesquisa (Auto)Biográfica, São Paulo, p. 1- 14, 2018.

LARROSA, Jorge. Tremores: escritos sobre a experiência; tradução Cristina Antunes, João Wanderley Geraldi. $-1^{\circ}$ ed.; $4^{\circ}$ reimp.; - Belo Horizonte: Autêntica Editora, 2019.

VIGOTSKI, Lev Semyonovich. A construção do pensamento e da linguagem; tradução Paulo Bezerra. $2^{\circ}$ ed. - São Paulo: Editora WMF Martins Fontes, 2009.

Recebido em: 18/05/2020.

Revisto em: 03/08/2020.

Aceito em: 11/08/2020. 
Notas

i Doutoranda em Educação no Programa de Pós-Graduação em Educação da Universidade Federal Fluminense (PPGEducação/UFF). Cursou Mestrado Acadêmico em Educação no PPGEducação/UFF (2018). Graduação em Física Licenciatura pelo Instituto de Física da Universidade Federal Fluminense (2011). Pesquisa os processos de formação de professores de Física e docência em física no Ensino Superior. E-mail: heriedna@gmail.com Niterói, Rio de Janeiro. ORCID: http://orcid.org/0000-0003-0388-924X

ii Importante destacar que [...] o recurso aos termos biografia e biográfica para designar, não a realidade factual da vivência, mas o campo de representações e de construções segundo as quais os seres humanos percebem sua existência, ressalta o quanto esta compreensão narrativa da experiência diz respeito a uma escritura, isto é, a um modo de apreensão e de interpretação da vivência, tendo sua dinâmica e sua sintaxe, seus motivos e suas figuras. (DELORY-MOMBERGER, 2012, p. 74).

iii CAPES - Coordenação de Aperfeiçoamento de Pessoal de Nível Superior - foi criada no ano 1951; é fundação do Ministério da Educação (MEC), desempenha papel fundamental na expansão e consolidação da pós-graduação stricto sensu (mestrado e doutorado) em todos os estados da Federação. As atividades da CAPES são agrupadas nas seguintes linhas de ação, cada qual desenvolvida por um conjunto estruturado de programas: avaliação da pós-graduação stricto sensu; acesso e divulgação da produção científica; investimentos na formação de recursos humanos de alto nível, no país e exterior; promoção da cooperação científica internacional; indução e fomento da formação inicial e continuada de professores para a educação básica nos formatos presencial e a distância. Adaptado de http://www.capes.gov.br/historia-e-missao. Acesso em 04 agosto 2020.

iv Vários textos foram lidos e discutidos no decorrer das aulas com a turma, entretanto nem todos entram na escrita deste texto porque ao narrar essa experiência não afilio-me a narrar cronologicamente os fatos/acontecimentos que perpassaram a disciplina nos seus diferentes dias e diálogos construídos com os sujeitos dentro e fora da sala de aula. 